
SMITH ON AN IMPROVED FORM OF OVEN, ETC.

\title{
XXXVI.-Note on an Improved Form of Oven for Heating Sealed Tubes, and avoiding Risks of Explosions.
}

By W'itson Smith, F.C.S., F.I.C., Assistant Lecturer and Demonstrator in Chemistry in the Owens College.

ANY one working much with sealed tubes, especially when high temperatures and resistance to great pressure are indispensable, may have observed that the usual forms of ovens in use generally possess some fault or drawback. For example, some are exceedingly safe in case of explosion, and the security of the thermometer is insured, but no temperature above $280^{\circ} \mathrm{C}$. can be attained by them except by means of an extraordinary expenditure of heat and gas, and to reach even that temperature, three, four, or even in some cases, five gas burners may be required. Then, again, a considerable time is frequently required before the desired temperature is attained, and yet it may be incurring risk to leave the oven and trust to chance in coming back and finding the temperature almost reached. Yet again, ovens frequently require a long time to cool down, so that the tubes may be removed safely; and it may be required, as in perchlorinations or perbrominations, to open the tube, allowing exit to gas under pressure, to re-seal and then heat again. Much time may thus be either gained or lost, according to the efficiency or inefficiency of the form of oven employed.

It would thus appear that the best form of oven should (1) be capable of being rapidly heated up to any desired temperature, of course within reasonable limit. (2) It should be safe, both as regards the person and the thermometer. (3) It should be as simple as possible in construction, so as to render quick manipulation possible. It should require as little expenditure of gas as possible, which means, heat should be economised as much as possible by it. (5) Finally, it should be capable of cooling down in as short a time as might be required, and this condition should be under a certain amount of control. I have recently had a form of oven constructed to fulfil all these requirements, which it does very satisfactorily. With one moderately large sized Bunsen burner, a temperature of about $420^{\circ}$ to $440^{\circ} \mathrm{C}$. can be obtained, and that in the course of a few minutes.

The following is a description of the oven:-Fig. 1 represents the internal body or tube-case of the oven, which would have been cylindri- 
cal had it not been flattened below, as is best seen in the section, Fig. 2 . It is made of strong sheet iron, the walls of the tubes being composed of stronger and thicker metal. The plate at the closed end of the oven is also of strong metal. There is a rim projecting about oneeighth of an inch above the body of the case, at either end, so that a space is left between the latter and its cover, Fig. 3, when the cover is adjusted upon it. At $(a)$ is a tube passing an inch or two vertically downwards amongst the other tubes lying parallel. This tube exactly faces one in the cover, and in it is fitted a piece of glass combustion tube with a perforated cork, through which the thermometer is inserted. The piece of glass tube projects through the hole in the cover, so that the thermometer may be adjusted after the cover is in its place. As is seen in Fig. 1, the oven is inclined by standing in an iron frame with the hinder legs shorter than the fore legs. $b b$ are pieces of iron with holes to admit the rods $c c$ of the cover, which act as guiders. If the ends of these guiding-rods be furnished with a screw-thread, and a nut be fixed on each after adjusting the cover, the security of the thermometer in case of an extraordinarily violent explosion is perfectly secured. $f f$ are handles by which the cover is lifted. $e e$ are thick pieces of lead to weight the lid, and offer resistance in case of explosions; they form the ends of the cover. Fig. 4 shows the oven with lid and thermometer adjusted. At $d$, Fig. 3 , in the cover, is a hole with cover or lid working on a hinge or screw, by which the hole can be wholly or partially closed. At the close of a heating up, if this hole be opened wide, after extinguishing the lamp, the oven is rapidly cooled by the current of air circulating around the space between the cover and tube-case, and passing out at the hole $d$.

All the apparatus here referred to, with the exception of the glass portion of it, may be had from Mr. Edmund Hargreaves, Higher Ormond Street, near Owens College. 